\title{
WILDERNESS INSTRUCTOR
}

\section{Injury and Illness in College Outdoor Education}

\author{
Flavio G. Gaudio, MD; Peter W. Greenwald, MD; Mark Holton, PhD \\ From the Department of Emergency Medicine, New York-Weill Cornell Medical Center, New York, NY (Drs. Gaudio and Greenwald); and \\ the Department of Athletics, Cornell University, Ithaca, NY (Dr. Holton).
}

\begin{abstract}
Objective.-Many colleges offer outdoor education courses such as rock climbing, kayaking, and mountain biking. Since these sports may be perceived as dangerous, we describe the prevalence of injuries and illnesses in a large, university-based outdoor education program. We also compare composite incident rates from this outdoor program to those of traditional college sports.

Methods.-Cohort of college students participating in either Cornell Outdoor Education (COE) or National Collegiate Athletic Association (NCAA) sports and comparison of incident rates. COE data were prospectively collected in the field; and NCAA data were prospectively collected through the Association's Injury Surveillance System. By definition, a COE injury or illness required follow-up care, prescription medication, or limited course participation. Similarly, a NCAA injury limited further practice or play. Incident rates were calculated as injuries and illnesses per 1000 participant-days (COE) or injuries per 1000 athlete-exposures (NCAA).

Results.-Included COE courses during 2002-2007 totaled 74005 participant-days. There were 111 injuries and illnesses, rate $=1.50 / 1000$ participant-days (95\% CI $1.24-1.81$ ). The NCAA reported 32646899 athlete-exposures during 1988-2004 and 181476 injuries, rate $=5.56 / 1000$ athleteexposures (95\% CI 5.53-5.58). Compared to COE, the relative risk of injury in NCAA sports was 3.7 (95\% CI 3.1-4.5) overall and 3.3 (95\% CI 2.8-4.0) after excluding the high-contact sports of football, ice hockey, and wrestling. For COE, mountain biking had the highest incident rate (7.5/1000), which was significantly lower than game injury rates in NCAA football and soccer. The most common injuries for both NCAA and COE were soft-tissue injuries such as sprains and strains.

Conclusion.-Outdoor education at this university-sponsored program was at least as safe as traditional college sports. Overall, college students were less likely to be injured while participating in COE courses than while participating in NCAA sports, even after excluding high-contact sports from the comparison.
\end{abstract}

\section{Introduction}

Courses in outdoor education are popular at colleges and universities throughout the United States. In fact, colleges and universities in over 36 states support through institutional membership the Association of Outdoor Recreation and Education or the Association for Experiential Education. ${ }^{1,2}$ While much has been written on the epidemiology of injury in traditional college sports such as football, basketball, or soccer, ${ }^{3}$ little has been written on the safety profile of college programs in outdoor education. Indeed, outdoor education, which evokes images such as climbing walls of rock or ice, hiking over

Reprints are not available from the authors. The authors report no financial conflict of interests or outside sources of funding for this study.

Corresponding author: Flavio G. Gaudio, MD, Department of Emergency Medicine, New York-Weill Cornell Medical Center, 525 East 68th Street, New York, NY 10065 (e-mail: flg9002@med.cornell.edu). mountain passes, and kayaking through white-water rapids, would seem to be inherently dangerous.

To explore the extent of this apparent danger, we present a study on the patterns of injury and illness in a large, university-based, outdoor education program. Cornell University's program enrolls nearly 5000 participants in over 300 outdoor education courses each year. ${ }^{4}$ While Gentile et $\mathrm{al}^{5}$ and McIntosh et $\mathrm{al}^{6}$ have written on the patterns of injury and illness in wilderness expeditions, our study is the first to focus on such patterns among college students in a university-sponsored, outdoor education program.

\section{Methods}

Our study was based on all injuries and illnesses reported by Cornell Outdoor Education (COE) during the years 2002 to 2007. During each course, instructors reported 
such incidents on standardized forms. Later, information from these forms was entered into computer-based spreadsheets (Microsoft Excel). Each spreadsheet listed the number of students and instructors in each course; as well as the number, nature, and context of course-associated injuries and illnesses.

We defined medically significant injury or illness using guidelines developed by the national Wilderness Risk Managers Committee. ${ }^{7}$ Based on these guidelines, minor injuries such as simple scrapes or small bruises that did not affect course participation were not included. Included injuries or illnesses required follow-up care either in the field or out; required prescription medications; or limited or precluded continued course participation.

As in Gentile et al's work, injury and illness rates were calculated using the denominator of participant-days. ${ }^{5}$ Participant-days were derived by multiplying the number of course participants by the length of the course in days. For example, a mountaineering course with 10 students lasting 14 days would give 140 participant-days.

Unlike Gentile et al's or McIntosh et al's work, however, our study did not include course instructors as participants in calculating participant-days. ${ }^{5,6} \mathrm{COE}$ instructors ranged in age from 18 to over 60 years old; and we excluded this group to make the cohort of participants in outdoor education comparable in age to National Collegiate Athletic Association (NCAA) athletes. Similarly, we excluded COE courses designed for graduate students, professional groups, and members of the community at large.

We compared COE incident rates to injury rates taken from the NCAA's Injury Surveillance System, which tracks injuries from a representative sample of college athletes participating in the following sports: softball, baseball, lacrosse, basketball, ice and field hockey, soccer, football, volleyball, gymnastics, and wrestling. ${ }^{8}$ Based on these data, we obtained a composite injury rate which included both men's and women's leagues where applicable. In addition, we also calculated a modified, composite NCAA rate which excluded injury rates for football, ice hockey, and wrestling. In this way, we could compare COE incident rates to a modified NCAA injury rate removed of the potentially polarizing effect of highcontact sports.

Similar to COE incident rates, which were based on participant-days, NCAA rates were based on athleteexposures: 1 athlete participating in either 1 practice or 1 game equaled 1 athlete-exposure. Furthermore, by definition, an NCAA injury required medical care either in the field or out; and limited or precluded athletic participation for at least 1 day beyond the day of injury. ${ }^{8}$ Comparisons between incident rates in COE programs and NCAA sports were expressed in terms of relative risk. The adjusted Wald formula was used to calculate relevant confidence intervals.

All data reviewed for the study did not include student names or identifying information. The University's Institutional Review Board granted the study an exemption from review.

\section{Results}

From 2002 to 2007, COE courses and programs included in the study totaled 74005 participant-days. Courses took place in New York, Vermont, New Hampshire, Pennsylvania, West Virginia, Texas, Arizona, Utah, Nevada, Washington, Alaska, Canada, and Costa Rica. Table 1 lists the enrollment in participant-days, as well as the number of incidents and evacuations, for each $\mathrm{COE}$ activity. The word "incident" may describe either an injury or an illness.

For all courses, there were 111 injuries and illnesses, for an overall rate of 1.50 incidents per 1000 participantdays. Of these incidents, 32 were serious enough to require student evacuation from the field or program site, so that $28.8 \%$ of all injuries and illnesses required evacuation. In addition, there were 2 students evacuated for lacking the physical fitness to complete an Alaska mountaineering course. These evacuations were included in

Table 1. COE course enrollments, incidents, and evacuations, 2002-2007

\begin{tabular}{lccc}
\hline \multicolumn{1}{c}{ Activity } & $\begin{array}{c}\text { Participant- } \\
\text { days }\end{array}$ & Incidents & Evacuations \\
\hline Climbing, constructed & 47422 & 18 & 7 \\
$\quad$ walls ${ }^{a}$ & & & \\
Backpacking/camping & 7937 & 37 & 10 \\
Wilderness medicine & 3498 & 4 & 1 \\
Climbing, natural & 2795 & 14 & 4 \\
$\quad$ surfaces & & & \\
River kayaking & 2054 & 9 & 1 \\
Day hiking & 1975 & 4 & 0 \\
Cross-country skiing & 1506 & 4 & 2 \\
Canoeing & 1332 & 1 & 0 \\
Sea kayaking & 1123 & 1 & 0 \\
Mountain biking & 1073 & 8 & 5 \\
Trail running & 747 & 3 & 1 \\
Caving & 623 & 1 & 1 \\
Snowshoeing & 592 & 0 & 0 \\
Telemark skiing & 545 & 3 & 0 \\
Mountaineering & 490 & 3 & 2 \\
Ice climbing & 293 & 1 & 0 \\
Total & 74005 & 111 & 34 \\
& & & \\
\hline
\end{tabular}

${ }^{a} 160 \mathrm{ft}$ wide, $30 \mathrm{ft}$ high. 
Table 2. COE composite rates of injury, illness, and evacuation, 2002-2007

\begin{tabular}{lcc}
\hline Cornell outdoor education & $2002-2007$ & $(95 \%$ CI $)$ \\
\hline Participant-days & 74005 & \\
$\quad$ Male & $51 \%$ & \\
Female & $49 \%$ & \\
Total incidents & 111 & \\
Injury/illness rate & & \\
Male & 1.50 & $(1.24-1.81)$ \\
Female & $51 \%$ & \\
Evacuation rate & & \\
Male & $49 \%$ & \\
Female & 0.46 & $(0.33-0.64)$ \\
\end{tabular}

${ }^{a}$ Per 1000 participant-days.

the evacuation data, but not the injury and illness data. Overall, then, there were 0.46 evacuations per 1000 participant-days. Course enrollments, incidents, and evacuations were divided equally among male and female students. These results, with the corresponding $95 \%$ confidence intervals (CI), are summarized in Table 2.

In contrast, during 1988 to 2004, the NCAA's Injury Surveillance System reported 181476 injuries per 32646899 athlete-exposures, giving an overall injury rate of 5.56/ 1000 athlete-exposures. ${ }^{3}$ More specifically, the game injury rate was $13.79 / 1000$; and the practice injury rate was $3.98 / 1000$. Excluding injury data from the highcontact sports of football, ice hockey, and wrestling gave a modified injury rate of $4.99 / 1000$ overall; as well a modified game injury rate of $8.45 / 1000$ and practice injury rate of 3.92/1000. These results are summarized in Table 3.

Compared to COE, the relative risk of injury in NCAA sports was 3.7 (95\% CI 3.1-4.5) overall and 3.3 (95\% CI $2.8-4.0)$ after excluding the high-contact sports of foot- ball, ice hockey, and wrestling. More specifically, the relative risk of injury in NCAA games or matches was 9.2 (95\% CI 7.6-11.1) overall and 5.6 (95\% CI 4.7-6.8) after excluding high-contact sports. In addition, the relative risk of injury in NCAA practices was 2.7 overall and 2.6 (95\% CI 2.2-3.2) after excluding high-contact sports.

For $\mathrm{COE}$, mountain biking had the highest injury rate (7.5/1000), attributable mainly to falls and crashes over rough or steep terrain. Figure 1 graphs the injury and illness rates for all COE courses. In comparison, COE's highest rate was significantly lower, based on $95 \% \mathrm{CI}$, than game injury rates for NCAA football (35.9/1000) as well as men's and women's soccer (respectively, 18.8 and 16.4/1 000). Figure 2 graphs the injury rates, with 95\% CI, for selected NCAA sports and COE courses.

Other statistical comparisons, permitted by non-overlapping 95\% CI, included that rock climbing (natural surfaces) had a lower incident rate (5.0/1000) than NCAA men's basketball games (9.9/1000). Moreover, incident rates in river or whitewater kayaking (4.4/1000) were lower than in NCAA women's gymnastics matches $(15.2 / 1000)$.

The majority of incidents $(57 \%)$ at COE were softtissue injuries, which included sprains and strains, contusions, lacerations, abrasions, and puncture wounds. The predominance of sprains, strains, and contusions was mirrored in the NCAA injury data. ${ }^{3}$ The most prevalent illnesses at COE were allergic reactions, asthma exacerbations, and gastroenteritis. Figure 3 depicts the breakdown by percentage of all COE injuries and illnesses during the study.

Sprains and strains at COE predominantly involved the lower extremity-particularly the ankle (52\%). Figure 4 graphs the location by percentage of all sprains and strains during the study. There were also 10 fractures or

Table 3. NCAA composite and modified (without high-contact sports) injury rates, 1988-2004

\begin{tabular}{lccc}
\hline \multicolumn{1}{c}{ NCAA sports } & 1988-2004 & Relative risk vs. COE (95\% CI) \\
\hline Athlete-exposures & 32646899 & & \\
Male & $57 \%$ & & \\
Female & $43 \%$ & & $3.7(3.1-4.5)$ \\
Total incidents & 476 & $(5.53-5.58)$ & $9.2(7.6-11.1)$ \\
Composite injury rate & 5.56 & $(13.69-13.89)$ & $2.7(2.2-3.2)$ \\
During games & 13.79 & $(3.96-4.01)$ & $3.3(2.8-4.0)$ \\
During practices & 3.98 & $(4.95-5.02)$ & $5.6(4.7-6.8)$ \\
Modified injury rate & & $(8.36-8.54)$ & $2.6(2.2-3.2)$ \\
During games & 4.99 & $(3.89-3.96)$ & \\
During practices & 8.45 & 3.92 & \\
\hline
\end{tabular}

Relative risk of injury for all NCAA sports compared with all COE activities.

${ }^{a}$ Per 1000 athlete-exposures. 


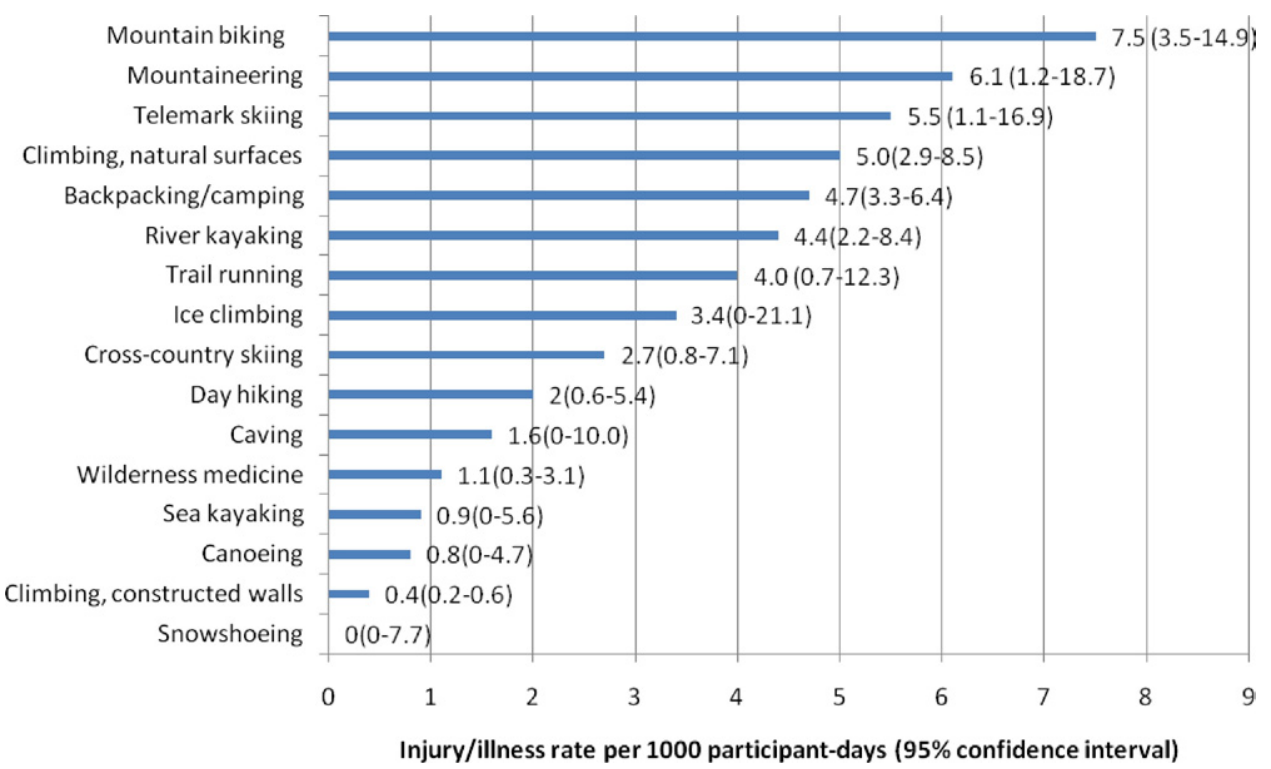

Figure 1. COE injury and illness rates by course, 2002 to 2007.

dislocations, rate $=0.14 / 1000(95 \%$ CI $0.07-0.25)$. In comparison, the incidence of fractures in NCAA sports ranged from $0.09 / 1000$ (95\% CI 0.07-0.11) in baseball games (hand fractures) to $0.33 / 1000$ (95\% CI $0.29-0.37$ ) in football games (lower extremity fractures). ${ }^{9,10}$ Table 4 lists the location of COE fractures and dislocations.

Mountain biking had the highest evacuation rate for COE (4.7/1000), followed by mountaineering (4.1/ 1000). Figure 5 graphs the evacuation rates for all COE courses. Fractures and dislocations were the injuries responsible for the highest number of COE evacuations
(29\%). Gastrointestinal conditions were the illnesses responsible for the highest number of $\mathrm{COE}$ evacuations (9\%). Figure 6 depicts by percentage all the reasons for student evacuations.

Head injury or concussion accounted for $4 \%$ of all COE incidents and, in comparison, 5\% of NCAA injuries. At COE, all head injuries resulting from a significant mechanism or force were evacuated from the field as a precaution. No COE student suffered any serious or lasting neurological damage as a result of a head injury.

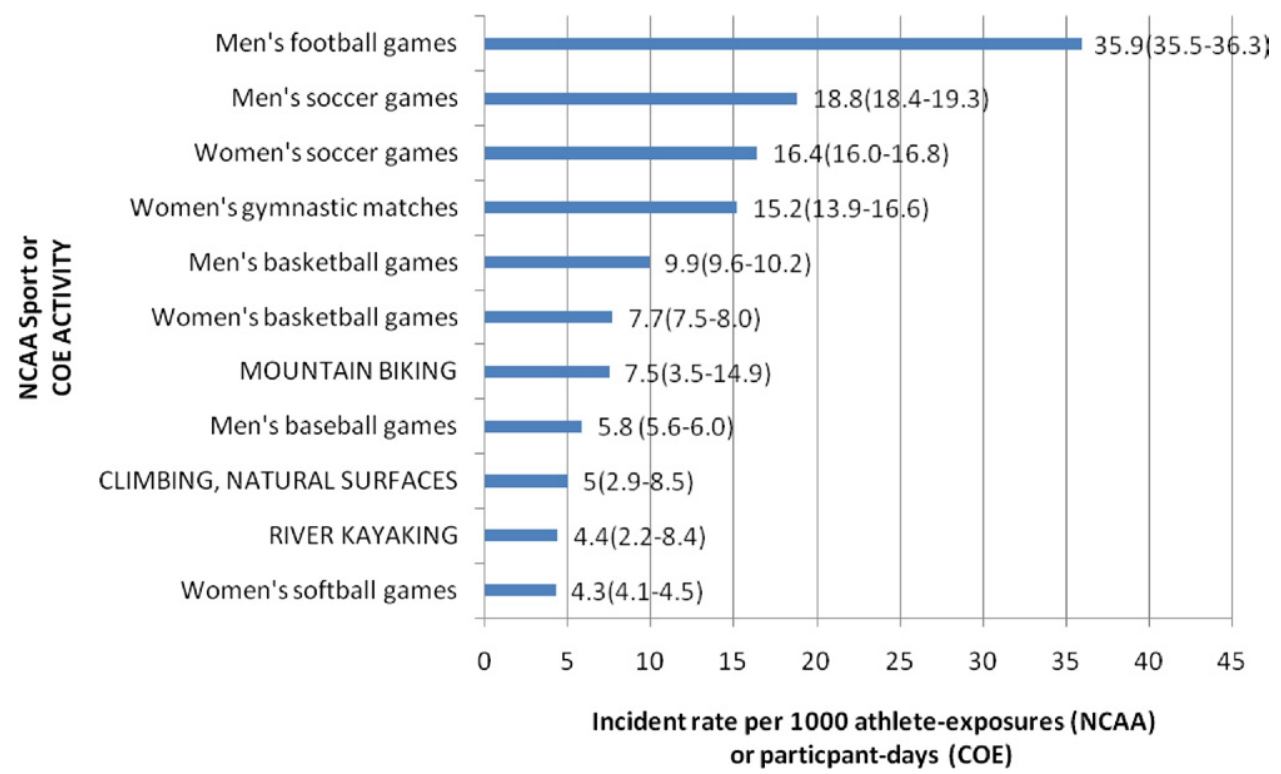

Figure 2. Comparison of incident rates from selected NCAA sports ${ }^{2}$ and COE activities. 


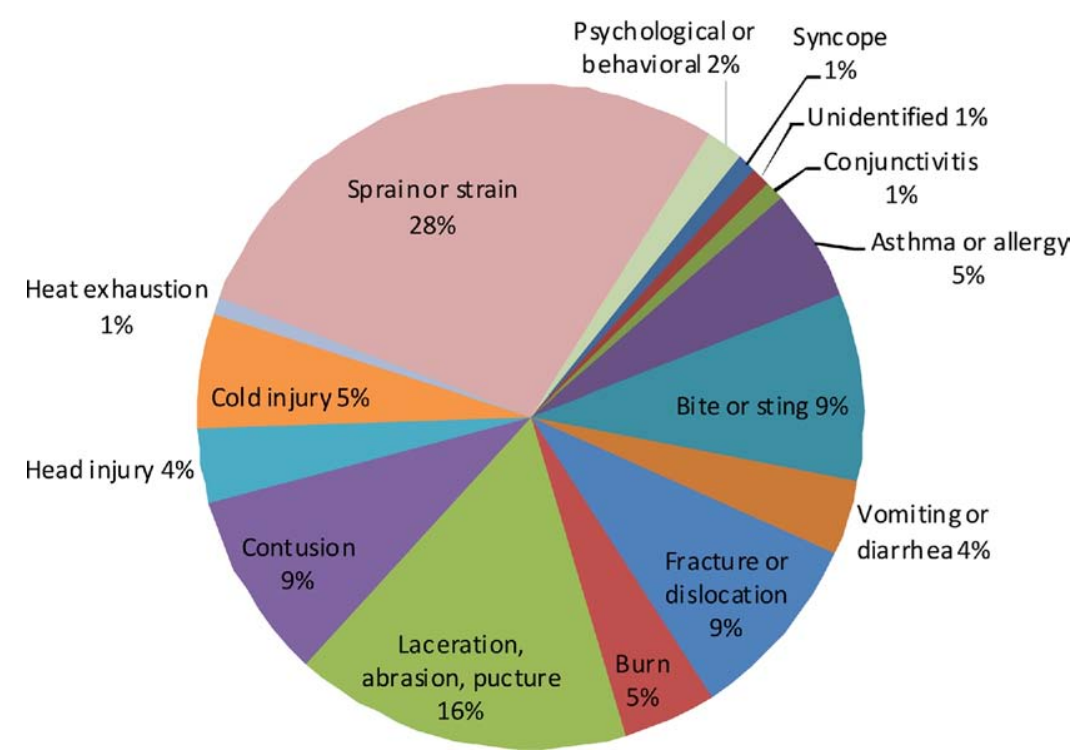

Figure 3. Breakdown of all COE injuries and illnesses, 2002 to $2007(n=111)$.

There were 10 animal bites or insect stings during the 6-year study period (rate $=0.14 / 1000$ participant-days, 95\% CI 0.06-0.25). Almost all stings that occurred during COE programs were by the Hymenoptera order (bees, hornets, wasps, and yellow-jackets). While some stings caused local swelling or regional reactions, none caused anaphylaxis. In fact, there was not a single case of anaphylaxis during the study period, whether to stings, food, medications, or other causes.

Finally, there were no fatalities at $\mathrm{COE}$ during the study period or since the founding of the organization in 1972.

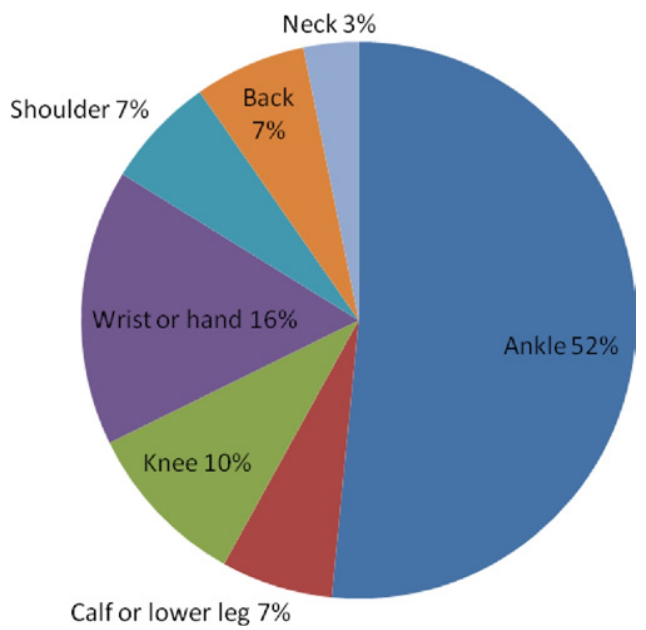

Figure 4. Location of sprains and strains $(n=31)$, rounded totals $>100 \%$.

\section{Discussion}

Our study found outdoor education courses at a university-sponsored program to be quite safe, with an overall rate of 1.50 injuries or illnesses per 1000 participantdays. Indeed, in comparing total incidents for Cornell Outdoor Education (2002-2007) and intercollegiate athletics (1988-2004), college students were at least 5 times more likely to be injured while participating in NCAA games or matches than in COE-sponsored programs. This comparison did not include the high-contact sports of football, ice hockey, and wrestling-which would have increased the NCAA injury rate during games or matches to 9 times the COE rate. Furthermore, a college student was at least 2 times more likely to be injured during NCAA training events or team practices than during a COE activity, regardless of whether high-contact sports were included in the comparison.

Table 4. Distribution of COE fractures

\begin{tabular}{lr}
\hline COE fractures 2002-2007 & No. \\
\hline Ankle or foot & 3 \\
Clavicle & 1 \\
Coccycx & 1 \\
Nose & 1 \\
Shoulder, ant. dislocation & 2 \\
Tibia-fibula & 1 \\
Wrist & 1 \\
Total & 10
\end{tabular}




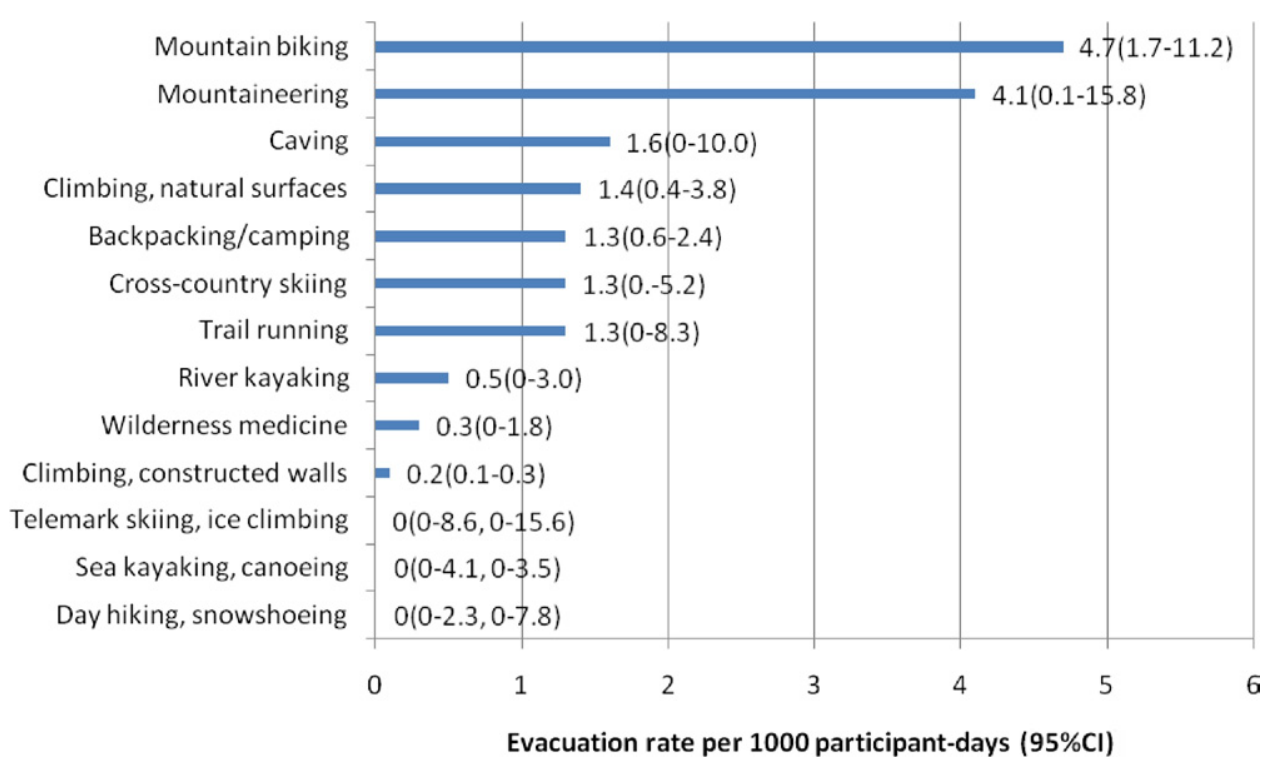

Figure 5. COE evacuation rates by course.

What made Cornell Outdoor Education programs as safe as-or even safer than-traditional college sports? A culture of safety permeates the organization's operations. Instructors review proper techniques and precautions before each course. In the field, redundant safety measures are the norm-for example, back-up ropes and anchors on high traverses. After each course, an equipment team inspects and services returned equipment. Moreover, a risk-management team analyzes all program-related incidents and "near misses"-events that could have led to injury-to help prevent future incidents. Finally, to prevent, recognize, and treat injury or illness, all instructors receive advanced training in fieldbased first aid or wilderness medicine.

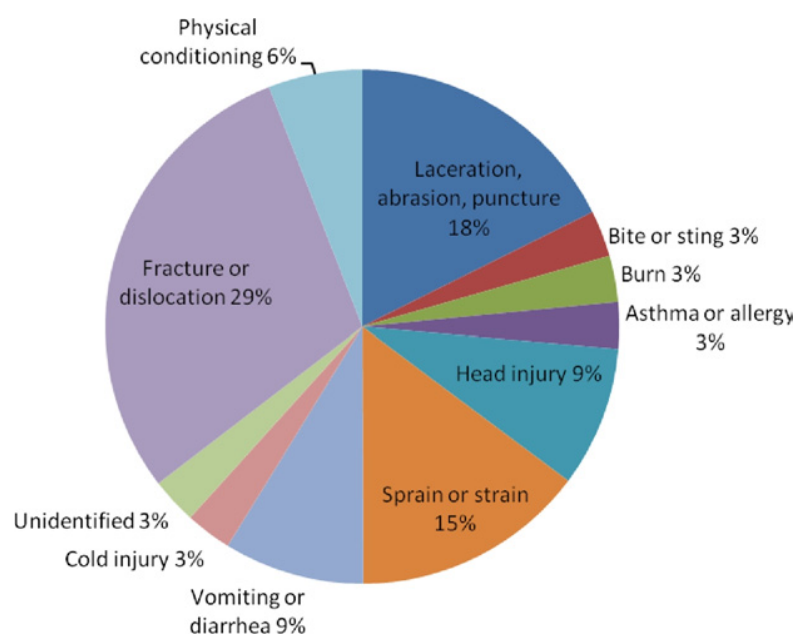

Figure 6. Reasons for student evacuations from COE courses $(n=$ 34 ), rounded totals $>100 \%$.
Ironically, in teaching the treatment of injury or illness, COE's wilderness medicine courses also generated an incident rate (1.1/1000). Teaching wilderness medicine involves simulating highly realistic patient encounters in actual field conditions-which may involve inclement weather, rough terrain, dim light, and very excited student-rescuers. For these reasons, incidents did occur, and courses in wilderness medicine were included in the study data.

Climbing constructed walls was the most popular activity at COE and comprised the majority of participantdays-perhaps reflecting the popularity of climbing walls at schools and gyms in the United States. At 150 feet (45.7 meters) wide and 30 feet ( 9.1 meters) high, with holds of natural rock, Cornell's climbing wall posed a risk of significant injury from fall; yet the incident rate for this activity was remarkably low (0.4/1000).

Overall, soft-tissue injuries comprised the majority of incidents at $\mathrm{COE}(57 \%)$. Instructors in programs like $\mathrm{COE}$, therefore, should be adept at treating these kinds of injury-especially the ankle sprain, which was the most common injury of all.

The high speeds and rough terrain of mountain biking led to more injuries from falls and crashes than in other COE courses. For this reason, mountain biking had the highest incident and evacuation rates. In response, COE instructors have, in briefings with students, emphasized the safe selection of routes and prudent speeds.

Mountaineering had the second highest incident and evacuation rates. The challenges of mountaineering include prolonged hiking and climbing at high altitude, where lower temperatures and oxygen levels lead to 
increased fatigue and the potential for mishaps. In addition to standard alpine safety practices, therefore, preexpedition selection of fit, disciplined participants is especially important in mountaineering courses-a lesson echoed by the evacuation of $2 \mathrm{COE}$ students from the Alaskan mountains for reasons of physical conditioning.

There were no cases of anaphylaxis during the study period. The COE data suggest that anaphylaxis, while understandably of great concern to parents and educators, actually occurs rarely in outdoor education. In fact, the National Outdoor Leadership School, which enrolls students both younger and older than college age, has recorded an anaphylaxis incidence of 2 cases in 20 years of operations, or 2 cases per 2.5 million participantdays. ${ }^{11}$ In comparison, in the United States, the risk of anaphylaxis in the general population is estimated at $0.05 \%$ to $2 \% .^{12}$

Food preparation in the field led to a surprising number of incidents beyond gastroenteritis. One-third of all cuts and lacerations during the study period were caused not by falling onto rough terrain, but from using camping knives to prepare meals. Moreover, the majority of burns were caused by flame or hot liquid, again in the fieldbased "kitchen." Such are the risks of preparing meals in the field-typically in situations where the lighting is dim and students are tired from the day's activities.

As for gastroenteritis, illnesses such as vomiting or diarrhea commonly arise from lapses in hygienic practices related to hand cleanliness, water purification, or food preparation. Indeed, as Leemon and Schimelpfenig have shown, teaching and enforcing strict hygiene with food preparation -including the use of alcohol-based sanitizing solutions for the hands-has more than halved the incidence of infectious diarrhea on wilderness expeditions. ${ }^{13}$

Given all the incidents related to food preparation, COE instructors have spent extra time on teaching students the proper use of camping stoves and knives; as well as on the implementation of strict hygienic practices. Future COE risk-management reviews will determine whether such efforts led to a decreased incidence of cooking-related injuries and illnesses.

Decreasing the incidence of all injuries and illness is, of course, the most important goal of risk-management; and we hope that this study will make a small contribution to that goal. Knowing the nature and prevalence of injuries and illness in any athletic program is the first step towards allocating resources and educational efforts to decrease such incidents.

\section{Limitations}

Calculating the relative risk of participation in NCAA sports versus $\mathrm{COE}$ programs implies that students in the
2 groups were comparable. While both COE participants and NCAA athletes were healthy, physically-active college students aged 18 to 22 years, the competitive drive and proclivity for injury may have been higher in NCAA athletes. In addition, there was a slight male predominance $(57 \%)$ among NCAA athletes compared to COE participants (51\% male). However, this predominance does not in itself explain the higher NCAA injury rates. In fact, the modified NCAA injury rates, by excluding men's football ( $40 \%$ of all athlete-exposures ${ }^{10}$ ), narrowed the male-female ratio and yet remained significantly higher than COE's incident rates.

The denominator participant-days (COE) may have represented a greater length of time than the athleteexposure (NCAA). While a NCAA athlete in practice or competition may have been active for several hours, a COE student on a multi-day trip may have been active for most of each day. Still, this possibility only would improve COE's safety profile, for as the denominator participant-days increases, COE incident rates would decrease.

Finally, the study was limited to data from one large, university-based outdoor program. Although safety practices in outdoor education have standard features, the safety profiles of outdoor programs may vary from college to college or region to region. Future study would do well to explore regional or even national trends in the safety of college outdoor education, similar to what the NCAA has done for its member schools.

\section{Conclusions}

For COE, a large, university-based outdoor education program, the high-intensity sports of mountain biking and mountaineering had higher incident and evacuation rates (although wider confidence intervals for these rates make us interpret the findings with caution). The majority of injuries at COE included sprains, strains, contusions, lacerations, abrasions, and puncture wounds. Of these, the ankle sprain was the most prevalent injury overall. Instructors at programs like COE should be adept at treating soft-tissue injuries. The most prevalent illnesses at COE were allergic reactions, asthma exacerbations, and gastroenteritis. Fractures and dislocations were the most common injuries that caused students to be evacuated from the field; vomiting and diarrhea were the most common illnesses requiring evacuation. Despite such incidents, we found outdoor education, using Cornell University's program as a model, to be quite safe, with an overall injury rate several times lower than a national, composite rate for NCAA sports. Colleges and universities which participate in traditional intercollegiate sports, yet seek to establish or expand programs in 
outdoor education, should find encouragement in the safety record of outdoor education that the present study revealed.

\section{Acknowledgments}

We are grateful to Neal Flomenbaum, MD, Physicianin-Chief of Emergency Medicine, New York-Weill Cornell Medical Center; and Todd Miner, PhD, Executive Director of Cornell Outdoor Education, for their steadfast support of Cornell Wilderness Medicine.

\section{References}

1. Association of Outdoor Recreation and Education. Available at: www.aore.org. Accessed December 1, 2008.

2. Association for Experiential Education. Available at: www. aee.org. Accessed December 1, 2008.

3. Hootman JM, Dick R, Agel J. Epidemiology of collegiate injuries for 15 sports: summary and recommendations for injury prevention initiatives. J Athl Train. 2007;42:311-319.

4. A narrative history of Cornell Outdoor Education. Available at: www.coe.cornell.edu. Accessed December 5, 2008.

5. Gentile DA, Morris JA, Schimelpfenig T, Bass SM, Auerbach PS. Wilderness injuries and illnesses. Ann Emerg Med. July 1992;21:853-861.
6. McIntosh SE, Leemon D, Visitacion J, Schimelpfenig T, Fosnocht $\mathrm{D}$. Medical incidents and evacuations on wilderness expeditions. Wilderness Environ Med. 2007;18:298-304.

7. Wilderness Risk Managers Committee. Guidelines for reporting incidents in outdoor education. Available at: http://www.aee.org/files/en/user/cms/WRMC_Incident_ Poster_text_2008.pdf. Accessed December 10, 2008.

8. Dick R, Agel J, Marshal SW. National Collegiate Athletic Association Injury Surveillance System commentaries: introduction and methods. J Athl Train. 2007;42:173-182.

9. Dick R, Sauers EL, Agel J, et al. Descriptive epidemiology of collegiate men's baseball injuries: NCAA Injury Surveillance System, 1988-2004. J Athl Train. 2007;42: 183-193.

10. Dick R, Ferrara MS, Agel J, et al. Descriptive epidemiology of collegiate men's football injuries: NCAA Injury Surveillance System, 1988-2004. J Athl Train. 2007;42: 221-233.

11. Schimelpfenig T. Epinephrine roundtable. Proceedings of Wilderness Medical Society; July 29, 2008; Snowmass, $\mathrm{CO}$.

12. Lieberman P, Camargo CA, Bohlke K, et al. Epidemiology of anaphylaxis. Ann Allergy Asthma Immunol. 2006;97: 596-602.

13. Leemon D, Schimelpfenig T. Wilderness injury, illness, and evacuation: National Outdoor Leadership School's incident profiles, 1999-2002. Wilderness Environ Med. 2003;14:174-182. 